\title{
Radionuclides and heavy metal concentrations as complementary tools for studying the impact of industrialization on the environment
}

\author{
Katarzyna Szarlowicz • Witold Reczynski • \\ Ryszard Misiak • Barbara Kubica
}

Received: 14 February 2013/Published online: 21 May 2013

(C) The Author(s) 2013. This article is published with open access at Springerlink.com

\begin{abstract}
The aim of the study was to determine whether using chemical and radiochemical analysis of lake sediments can highlight changes in the climate. Also it was studied whether human impact on the environment can be observed and to what extent such changes are in agreement with historical data. Samples of $16 \mathrm{~cm}$ thick sediment cores from the Smreczynski Staw Lake were collected and divided into $1 \mathrm{~cm}$ thick sub-samples. The samples were air dried and homogenized. The quantitative analysis of $\mathrm{Fe}$, $\mathrm{Mn}, \mathrm{Zn}, \mathrm{Cr}, \mathrm{Cu}, \mathrm{Ni}, \mathrm{Cd}$, and $\mathrm{Pb}$ in the digested sediment samples was made by using atomic absorption spectrometry. Simultaneously, the radioactivity of ${ }^{137} \mathrm{Cs}$ using gamma spectrometry and ${ }^{210} \mathrm{~Pb}_{\text {uns }}$ using alpha spectrometry, were measured for sediment layer dating. Results showed that iron concentration was in the range 0.3-over $1 \%(\mathrm{w} / \mathrm{w})$, and zinc $0.01-0.05 \%(\mathrm{w} / \mathrm{w})$. Lesser concentrations were found for copper 18.37-43.6 ppm, manganese $37.5-50.7 \mathrm{ppm}$, lead 146.1-432 ppm, chromium 12.3-37.4 ppm, nickel 3.1-10.8 ppm and cadmium $0.9-34.6 \mathrm{ppm}$. Changes in ${ }^{137} \mathrm{Cs}$ radioactivity was in the range of $89 \pm 11$ to $865 \pm 62\left(\mathrm{~Bq} \mathrm{~kg}^{-1}\right)$. Sediments composition can accurately reflect (in terms of time and to
\end{abstract}

K. Szarlowicz $(\bowtie) \cdot$ B. Kubica

Faculty of Energy and Fuels, AGH University of Science and Technology, al. A. Mickiewicza 30, 30-059 Kraków, Poland

e-mail: szarlowi@agh.edu.pl

W. Reczynski

Faculty of Material Science and Ceramics, AGH University

of Science and Technology, A. Mickiewicza 30,

30-059 Kraków, Poland

R. Misiak

The Henryk Niewodniczański Institute of Nuclear Physics Polish Academy of Sciences, ul. Radzikowskiego 152,

31-342 Kraków, Poland what extent) air pollution and natural geo-chemical processes in the environment. However, the choice of the analysed object is crucial in this respect. The Smreczynski Staw Lake, due to its location in the mountains and hydrological situation, proved to be very useful for providing undisturbed analytical samples.

Keywords Sediments core - Metals contamination · Radioactive cesium · Dating sediments

\section{Introduction}

General aspects

It is well recognized that "what goes up, must come down". Distribution of emitted elements and compounds depends on the physical phase (solid, gaseous or vapours) and climatic conditions (wind direction and speed, precipitation). But the fate of deposited contaminants is also dependant on numerous physical and chemical factors. The question is, whether one can draw useful information by referring to the history of contamination of a given region, from chemical analysis of available samples. Most often these are: soil and sediments, peat and ice core samples [25]. The Smreczynski Staw Lake is fed mainly by water from natural precipitation (snow and rain). On the one hand, the Tatras being high mountains means they are especially sensitive to the environmental impact of humans, whilst on the other, the history of anthropogenic environmental contamination might be observed through an analysis of sediments accumulated in mountainous lakes.

Tatra Mountains are the highest mountains massif within the whole Carpathian range. It is the only area in 
the Carpathians which has preserved a typical postglacial relief, hanging valleys, glacial cirques and numerous high-mountain oligotrophic lakes. The Tatra Mountains form the state frontier between Poland and Slovakia. The minor part (about one-fourth of the area) on the Northern slopes, is located in Poland (Fig. 1). These are relatively young mountains, formed during the Alpine orogeny, and are characterized by a diverse geological structure. The Tatras are rich in lakes and ponds, some of which can be very interesting to observe the impact of climate and environmental changes. One such lake is the Smreczynski Staw Lake, which is located in the Western Tatras at the beginning of the Koscieliska Valley and at the mouth of the Pysznanska Valley, at an elevation of $1225.9 \mathrm{~m}$ above sea level, with an average depth of $1.8 \mathrm{~m}$, a maximal depth of $5.3 \mathrm{~m}$ and a capacity of $13.54 \times 10^{3} \mathrm{~m}^{3}$ [13]. This lake is surrounded by a number of peaks reaching 2,000 m asl. (e.g. Bystra (2,178 $\mathrm{m}$ above sea level) Blyszcz $(2,158 \mathrm{~m}$ above sea level), Smreczynski Wierch (2,086 $\mathrm{m}$ above sea level). The lake is located in a Natural Reserve Forest.
Numerous contaminants considered as harmful for living organisms such as radionuclides and metals are often analyzed in parts of the ecosystem which tend to accumulate them; namely soil and sediments. Some radionuclides exist naturally in the environment. But there are also artificial radionuclides which contribute to total environmental radioactivity. It is very important to control the radioactive pollution. On the other hand radionuclides can be used in helping to date sediments.

Generally the process of determining the age of sediments is described as radiometric dating. In this type of research various radioisotopes are used. Every technique is based on the decay time of the radioisotope. Taking into account the geochronology of sediments, three techniques are most commonly used: the ${ }^{14} \mathrm{C},{ }^{210} \mathrm{~Pb}$, and ${ }^{137} \mathrm{Cs}$ methods.

The methods differ in timespan determination and in time resolution. Knowing the time of deposition of each layer of sediments, it is possible to link time with changes that have taken place in the analyzed area (e.g. erosion, values of sedimentation rate and mass accumulation rate, history of heavy metal pollution) $[7,22,26]$.
Fig. 1 Map of Poland (http://www.vidiani.com/ $? \mathrm{p}=16054)$

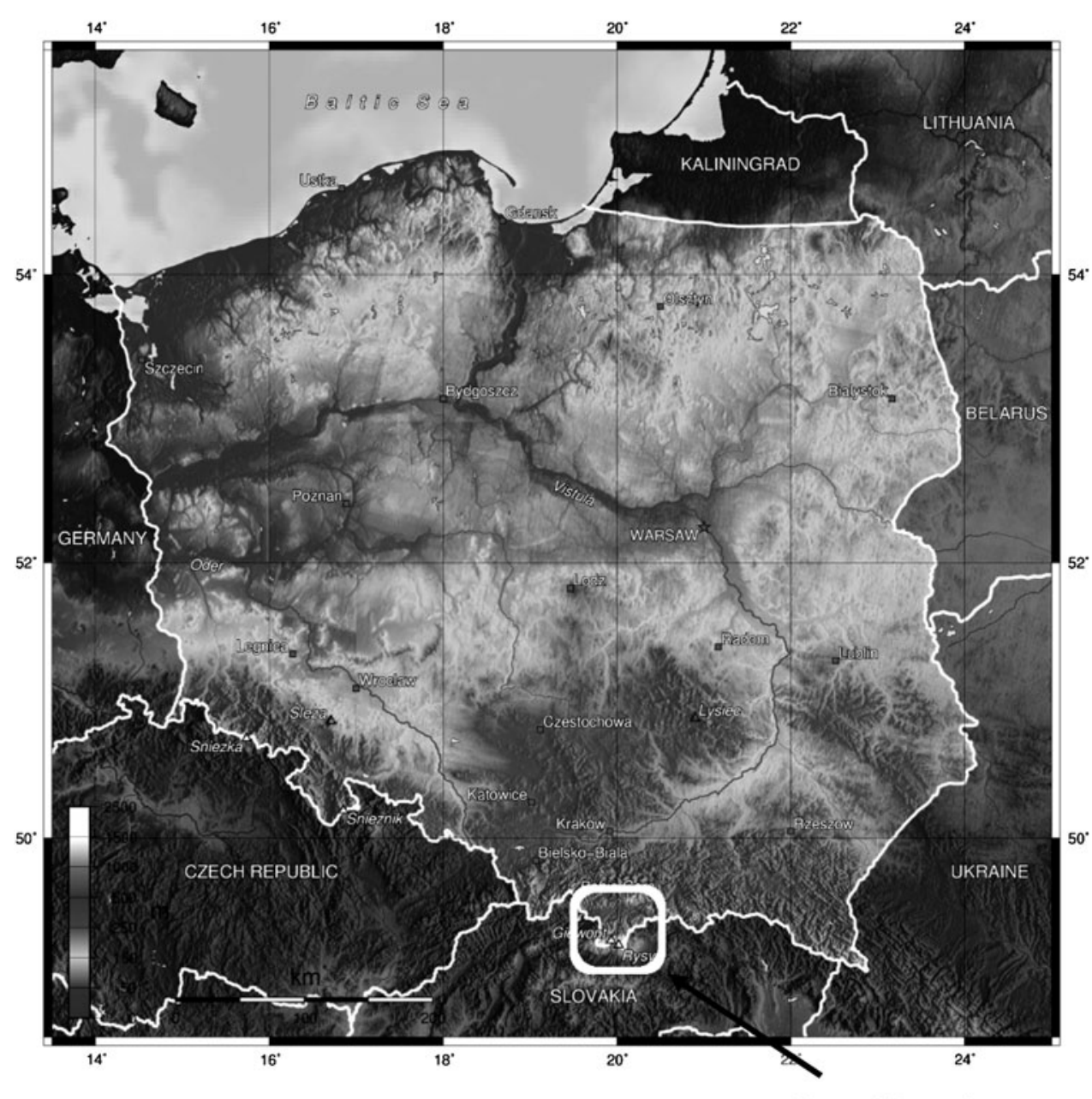

Tatra Mountains 
Sources of metal contamination can be natural and anthropogenic. By means of soil or sediment core samples which comprise "historic" information, it is not easy to distinguish and determine sources of contamination. The further back the analysis goes, greater the possibility of finding the main sources of contamination which in turn can be correlated with human activity and the state of the environment at the time. On the other hand, a water environment which consists of a water, sediments and living organisms should reflect the contamination history of a given region, which should be especially visible in the concentrations of contaminants found there. This is especially true for heavy metals such as $\mathrm{Cd}, \mathrm{Pb}, \mathrm{Ni}$, and $\mathrm{Cr}$, as these elements are readily adsorbed by sediment components such as clay minerals and organic matter $[10,14,31]$.

The aim of the study was to determine, based on chemical and radiochemical analysis of the sediments of the Smreczynski Staw Lake (a small lake in the Western Tatras), whether changes in the environment resulting from the impact of human activity, can be observed.

Sources of natural radionuclide- $-{ }^{210} \mathrm{~Pb}$

Natural radioactive isotopes such as lead $\left(\mathrm{T}_{1 / 2}=\right.$ 22.3 years) is the main decay product of the uraniumradium series. Due to the place of origin of the radioisotope ${ }^{210} \mathrm{~Pb}$ in the sediments, the following can be distinguished:

- ${ }^{210} \mathrm{~Pb}_{\text {sup }}$ (supported): it is formed in situ in the sediment. Its source is the ${ }^{222} \mathrm{Rn}$ as a result of radioactive decay of ${ }^{226} \mathrm{Ra}$ included in the sediments,

- ${ }^{210} \mathrm{~Pb}_{\text {uns }}$ (unsupported): its presence in the environment is closely related to the gas ${ }^{222} \mathrm{Rn}$. Radon is released from the geological environment and it decays outside the water body (in the atmosphere or in water flowing into the reservoir). The lead comes from this decay is deposited on aerosols and it is delivered to the water body, where it is adsorbed on suspended particles and then incorporated in the sediments [6].

Sources of ${ }^{137} \mathrm{Cs}$

Artificial radionuclides constitute a significant problem in terms of environmental protection. To this group belongs the long-life gamma radioisotope cesium ${ }^{137} \mathrm{Cs}$. Due to its long half-life (30.07 years) it is considered as an important indicator of radioactive pollution. There were two main sources in the world which are responsible for the presence of this radionuclide in the environment. These are: nuclear weapon tests which were carried out in the atmosphere during the 1950s and nuclear reactor catastrophes such as in Chernobyl in 1986, which released substantial amounts of $\alpha, \beta$ and $\gamma$-radionuclides into the atmosphere. The radionuclides were introduced to the stratosphere and were then distributed globally, before moving back into the troposphere before falling back to earth's surface as precipitation. The radionuclide cloud from Chernobyl moved with the wind over Poland, thereby contaminating the Tatra mountains.

From nuclear activities, about $948 \mathrm{PBq}$ of ${ }^{137} \mathrm{Cs}$ were introduced into the atmosphere due to nuclear weapon tests. In addition $85 \mathrm{PBq}$ of this radionuclide was added during the Chernobyl accident $[5,16]$.

What is significant is that this radionuclide is strongly absorbed into the sediments, thus the variation of ${ }^{137} \mathrm{Cs}$ radioactivity with depth in a core may yield chronostratigraphic features. That is why it can be treated as a time marker for the years 1955-1963 (maximum of cesium concentration) and 1986 (higher concentration of ${ }^{137} \mathrm{Cs}$ ) [30].

\section{Radiometric dating}

Lead and cesium methods are used to determine the age of both marine and freshwater sediments. Due to the short half-life of ${ }^{210} \mathrm{~Pb}$ (22.3 years), this method is appropriate for the dating of sediments not older than 150-200 years. The essence of this method is to calculate the radioactivity of unsupported lead in the sediment's core layers.

Anthropogenic ${ }^{137} \mathrm{Cs}$ was introduced into the environment through human activity. As was mentioned above, two main events (nuclear weapon test and the Chernobyl accident) were responsible for the high levels of this radionuclide in the environment. Therefore in a sediment core, two maxima (weapon tests 1963 year and Chernobyl 1986) of ${ }^{137} \mathrm{Cs}$ radioactivity should be present.

Thus, if we know the sampling date and time of the event, we can estimate the age of the layer in which the maximum level was presented [28].

Sources of heavy metal contamination in the Tatras

In the middle ages it was noted that in the mountains in Southern Poland, treasure hunters obtained a royal privilege to search for gold and precious stones and minerals. Some human activities, which may be considered as "industrial", are mentioned as early as the 15th century rapidly developing in the 18th and 19th centuries [17]. Initially, this activity covered mineral excavation of copper, silver and gold ores, and later iron ore. The ore mines were located on the slopes of Ornak, the Starorobocianska Valley and the Kominiarski Wierch Mountain above the Chocholowska Valley. The first steelworks were built in 1756 in Kuznice, and the first blast furnace was constructed in 1767 on the clearing called Stare Koscieliska. Other steel furnaces were located in Koscielisko and the Pyszna 
Pasture [4, 18]. Due to political and economical reasons the mineral excavation of metal ores ended in 1880 and, as a consequence, the metallurgy industry declined in the years immediate after. Despite metal ore mining and metallurgy, some other industrial and economic activities also took place in the Tatras, in quarries, sawmills, lime-works and two paper-mills. Most of the mentioned works were established in the 19th century and continued to operate until the 20th century [23]. Since 1956 the area has been protected by law through the founding of the Tatra Mountains National Park.

Mineral excavation lasting from the 15th to the 20th century in this region definitely had an impact on the local environment. Some of the mines and plants were located only a few kilometers from the Smreczynski Staw Lake (Fig. 2). But as a result of the second Industrial Revolution many big iron and steelworks were established in Central Europe. Among these, the steelworks in Trzyniec (Czech Republic) established in 1839, was the biggest in the region. From the 1850s onwards, mining and metallurgy in the Silesian region of Poland developed quickly, accompanied by an increase in the emission of harmful substances. This trend continued until the end of the 20th century. From 1964 onwards, the Trzyniec steelworks discharged annually into the atmosphere $\sim 130,000$ tones of fine grained dust, and 31,600 tones of $\mathrm{SO}_{2}$. Unfortunately for the Tatras, they are located to the east of Trzyniec and Silesia and during the year most of the winds come from the North-West and West, constantly transporting pollutants with them.
This long distance air transportation of pollutants undoubtedly included heavy metals. In Central Europe a drastic increase in emissions of toxic elements into the atmosphere was concomitant with the Industrial Revolution (19th century) and reaching its peak in the 1970s and 1980s ( $\mathrm{Cd}, \mathrm{Pb}, \mathrm{Hg})$ [25]. In the case of $\mathrm{Pb}$ this element has been linked to humans since the Roman Empire, but as a contaminant it was first introduced in high quantities into the environment from the 1920s onwards, as it is used as an additive to gasoline. The highest concentration of this element was found in Europe in the 1970s (up to 199,000 t in 1975) [25, 27].

Another factor which might influence changes in concentrations of elements in the soils or sediments is the presence of acid rain. Energy consumption and population growth in the last two centuries resulted in an increased production of sulphur and nitrogen oxides and release of these compounds into the atmosphere [29]. On the other hand, acid rains caused a leaching of immobilized elements from the soil and introduced them back into water systems. However, implementation of EU regulations led to a marked decrease in sulphur and nitrogen emissions, which in turn caused a $\mathrm{pH}$ increase in lakes and rivers [12]. This decreasing tendency has been visible in Europe since the late 1980s (there has been a decrease of around $30 \%$ in $\mathrm{NO}_{\mathrm{x}}$ concentration) [1]. The same tendencies apply to changes in sulphur oxide concentrations in the air. Noteworthy is the fact that air pollution in the Central European region used to be relatively high $[1,15]$.
Fig. 2 Metals and metallurgical centers in the Tatra Mountains

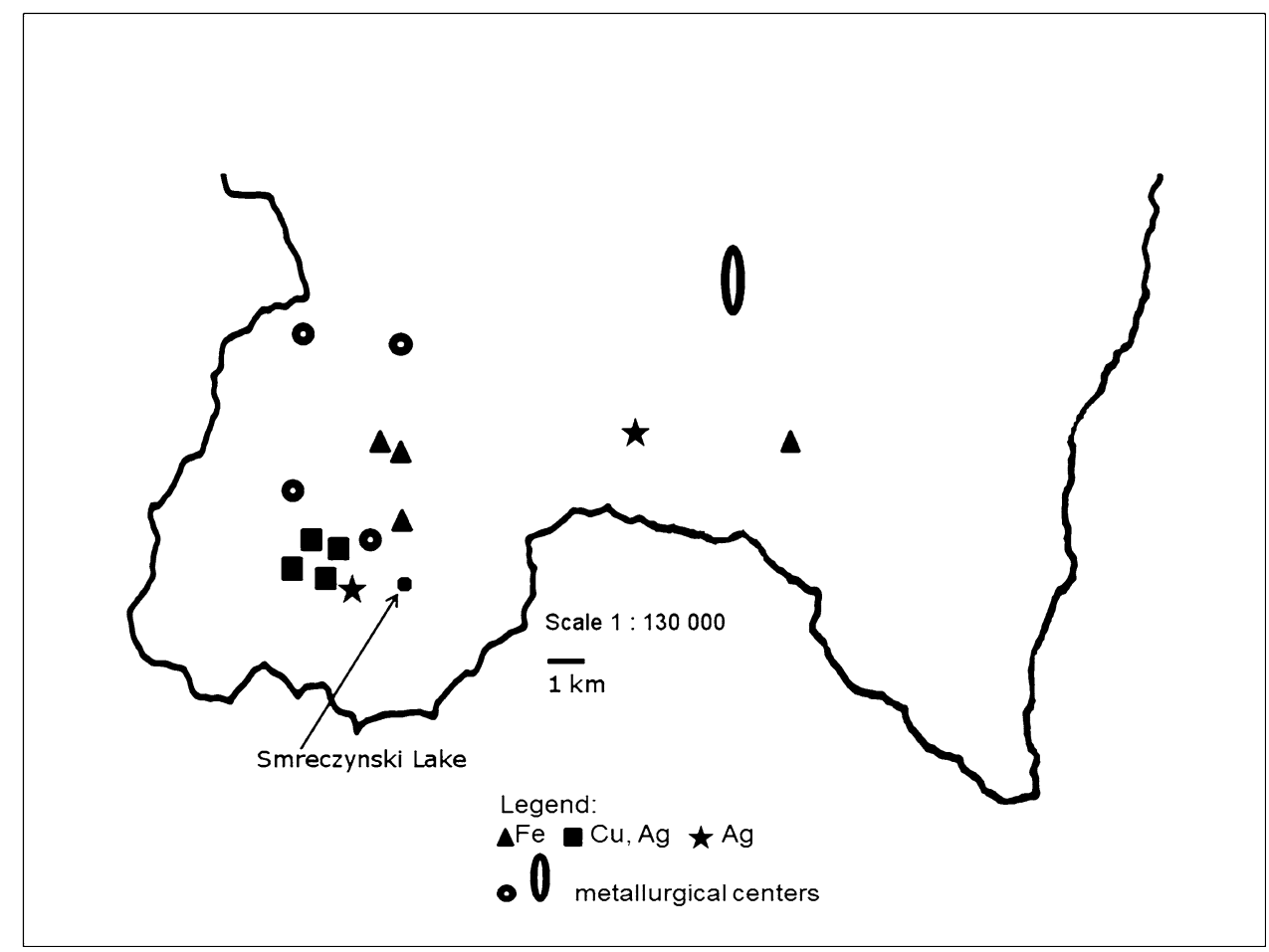




\section{Materials and methods}

Three sediment cores were collected almost from the middle of the Smreczynski Staw Lake. From the cores, three sets consisting of 16 ( $1 \mathrm{~cm}$ thick) sub-samples were separated and transferred to the laboratory in polyethylene containers. The top, loose layers of the sediments were eliminated. The sampling was done from a boat with the use of a Limnos corer (Poland). The samples were air dried, sieved on a vibrating screen $(<2 \mathrm{~mm})$ to eliminate small stones and not decomposed plant parts, and homogenized.

\section{Radionuclide's radioactivity measurements}

To estimated sediment core sub-sample age ${ }^{210} \mathrm{~Pb}_{\text {total }}$ radioactivity was determined. Although alpha spectrometry is a very demanding and time-consuming method, it is also characterized by low measurement uncertainty.

$\mathrm{Pb}_{\text {total }}$ was determined through its daughter ${ }^{210} \mathrm{Po}$ in radioactive equilibrium with its parent. ${ }^{210} \mathrm{~Pb}_{\text {total }}$ radioactivity was determined based on two depositions of polonium on a silver disc, with an interval of $\sim 6-8$ months. The Flynn method [11] was used in order to determine polonium radioactivity. First the samples (weighting about $0.1 \mathrm{~g}$ ) were wet digested in the microwave system using concentrated nitric and hydrochloric acids. Then the solution was evaporated until almost dry. Polonium was deposited on a silver disc from a hydroxylamine hydrochloride $(40 \%)$ solution, sodium citrate $(20 \%)$ solution and hydrochloric acid $\left(0.5 \mathrm{~mol} \mathrm{dm}^{-3}\right)$. The temperature of deposition was about $85-88{ }^{\circ} \mathrm{C}$ and time deposition was $3 \mathrm{~h}$. Alpha radioactivity was measured using an Ortec Alpha Spectrometer Soloist-U0450. One measurement lasted 3 days. The efficiency for the $5.3 \mathrm{MeV}$ alpha line of ${ }^{210} \mathrm{Po}$ was determined at $26 \pm 3 \%$. The system was calibrated in 4.8-5.8 MeV region of energy standard radioactive source ${ }^{209}$ Po and AMR-33.

All analyses were done with ${ }^{208} \mathrm{Po}$ (yield tracer) which was added in order to control the efficiency of the procedure. In general, the analytical precision was between 1 and $3 \%$ and accuracy between 1.5 and $5.2 \%$. While analyzing radioactivity (net peak area), better precision and accuracy is achieved for the samples characterized by a higher content of a given radioisotope, due to the higher number of registered counts.

The radioactivity of ${ }^{210} \mathrm{~Pb}_{\text {total }}$ was calculated using (1):

$A_{\mathrm{Pb}-210}=\frac{A_{2}-A_{02} \cdot \exp \left(-\lambda_{2} t\right)}{\frac{\lambda_{2}}{\lambda_{2}-\lambda_{1}} \cdot\left(\exp \left(-\lambda_{1} t\right)-\exp \left(-\lambda_{2} t\right)\right)}$

where $A_{\mathrm{Pb}-210}$ is the ${ }^{210} \mathrm{~Pb}_{\text {total }}$ radioactivity for the date of first deposition, $A_{02}$ is the ${ }^{210} \mathrm{Po}$ radioactivity (first deposition), $A_{2}$ is the ${ }^{210}$ Po radioactivity (second deposition), $\lambda_{2}$ is the decay constant of ${ }^{210} \mathrm{Po}, \lambda_{1}$ is the decay constant of ${ }^{210} \mathrm{~Pb}$ and $t$ is the time between depositions.

The method of gamma spectrometry is widely used to analyze radionuclide environment contamination. Methods using the radioactive tracers (for example ${ }^{137} \mathrm{Cs}$ ) are utilized to study natural processes such as soil erosion or lake sedimentation [9].

The radioactivity of ${ }^{137} \mathrm{Cs}$ was measured by means of gamma spectrometry. All samples were taken for gamma spectrometric measurements with a low-background gamma spectrometer equipped with an $\mathrm{HPGe}$ detector $(21 \%$ efficiency, $\mathrm{FWHM}=1.9 \mathrm{keV}) .{ }^{137} \mathrm{Cs}$ was determined via its gamma emission at $662 \mathrm{keV}$. The gamma ray spectra processing were performed with a Canbera and Ortec electronic system together with the Maestro programme. The spectrometer was calibrated using the standard IAEA-154. Each sample was measured for $72 \mathrm{~h}$. Radioactivity refers to the dry mass of the samples and the results were calculated for the day of sampling.

The radioactivity was calculated according to formula (2) [24]:

$A_{\mathrm{Cs}-137}=\frac{\left(\mathrm{CPS}_{\mathrm{s}}-\mathrm{CPS}_{\mathrm{b}}\right) \cdot 1000}{\varepsilon(E, h) \cdot P_{\gamma} \cdot T_{\mathrm{z}}(E, h, \rho) \cdot m}$

where $A_{\mathrm{Cs}-137}$ is the ${ }^{137} \mathrm{Cs}$ radioactivity $\left(\mathrm{Bq} \mathrm{kg}^{-1}\right), \mathrm{CPS}_{\mathrm{s}}$ counts per second (sample), $\mathrm{CPS}_{\mathrm{b}}$ is the counts per second (background), $\varepsilon$ is the efficiency, $P_{\gamma}$ is the probability of gamma quantum emission, $T_{\mathrm{z}}$ is the self-absorption coefficient and $m$ equals the mass.

Age, sedimentation rate and mass accumulation rate

The sum of these two components ${ }^{210} \mathrm{~Pb}_{\text {sup }}$ and ${ }^{210} \mathrm{~Pb}_{\text {uns }}$ gives the total radioactivity of ${ }^{210} \mathrm{~Pb}_{\text {total }}$. The presence of unsupported lead in the sediments may be used to determine its age. Using the law of radioactive decay, we can specify the time of deposition of each layer. Knowing the age of the layer, we can calculate the sedimentation rate. Obtaining this information is possible by using two models for determining the age of the sediment: the CRS (constant rate of supply) model and the CIC (constant initial concentration) model.

To calculate the age of the sediments the CRS model was used, because it takes into account variations in sedimentation rate and possible mixing of the sediments. The age was calculated according formula (3):

$t=\frac{1}{\lambda_{1}} \cdot \ln \left(\frac{A_{\infty}}{A_{x}}\right)$

where $t$ represent the age of the layer at the depth $x, A_{\infty}$ equals the accumulated radioactivity of ${ }^{210} \mathrm{~Pb}_{\text {uns }}$ in the 
whole core, $A_{\mathrm{x}}$ is the accumulated radioactivity of ${ }^{210} \mathrm{~Pb}_{\text {uns }}$ in the core below depth $x$.

The estimated age was used to calculate the sedimentation rate for each layer. Sedimentation rate was calculated using formula (4):

$r_{x}=\frac{x_{n}-x_{n-1}}{t_{n}-t_{n-1}}$

where $r_{x}$ is the sedimentation rate for the interval between centres of the $x-1$ and $x$-th layer, $x_{n}$ is depth and $t_{n}$ is the age of the $n$-th layer.

Using the CRS model the mass accumulation rate was estimated (5):

$r(x)=\frac{\lambda \cdot A_{\mathrm{c}}(x)}{A_{x} \cdot 1000}$

where $A_{\mathrm{c}}(x)$ is the ${ }^{210} \mathrm{~Pb}_{\text {uns }}$ radioactivity for the $x$ layer $\left(\mathrm{Bq} \mathrm{cm}{ }^{-2}\right.$ ) and $A_{x}$ is the ${ }^{210} \mathrm{~Pb}_{\text {uns }}$ radioactivity for the $x$ layer $\left(\mathrm{Bq} \mathrm{kg}{ }^{-1}\right)[19,21]$.

Elemental quantitative analysis

The dry sediment core samples were wet digested in a microwave system (Anton Paar Multiwave 3000, Switzerland) with a mixture of concentrated nitric $(6 \mathrm{ml})$ and perchloric acids $(200 \mu \mathrm{l})$ (suprapure, Merck, Germany). The reagent excess was evaporated on a hot plate in a quartz vessel. Quadruple distilled water was used for glassware preparation and sample dilution.

The quantitative analysis of $\mathrm{Mn}, \mathrm{Fe}, \mathrm{Cu}$ and $\mathrm{Zn}$ was performed by using atomic absorption spectrometry method, flame technique (FAAS) in standard conditions. Concentrations of $\mathrm{Cd}, \mathrm{Cr}, \mathrm{Ni}$, and $\mathrm{Pb}$ were determined using the AAS method, electrothermal technique (ETAAS). For measurements, the pyrolitic coated graphite furnaces were used. For all measurements the Perkin Elmer spectrometer Model 3110, equipped with the HGA-600 graphite furnace was used. Experimental conditions for ETAAS measurements were optimized using the Method Development Programme.

All measurements were made in triplicate. Analyses were made for each core sub-sample separately and the presented quantitative data represents the mean values (comprising information from all three collected cores).

The accuracy of the developed analytical procedure was checked by the analysis of the certified reference material-BCR 380 "River Sediment". Satisfactory agreement with the certified values of concentrations of the elements was achieved.

In addition pore water $\mathrm{pH}$, total organic carbon and grain size distribution of the sediments were analysed using standard methods.

\section{Results and discussion}

The Tatras form a sharp and high (up to 2,600 $\mathrm{m}$ asl.) mountain ridge that dominates the surrounding area. The Western Tatras bedrock comprises dolomites and limestones and the soil cover is composed of various types of rendzinas [20]. The Koscieliska Valley (in the vicinity of the Smreczynski Staw Lake) is the place where human activity involving the extraction and processing of metals started in the 15th century (copper mine) and later by the end of 19th century, also included an iron ore mine and smelter. Industrialization, which took place in this part of Poland and Slovakia in the 19th and 20th centuries, should be reflected in the composition of the sediments.

The core layers of these sediments were estimated, using the ${ }^{210} \mathrm{~Pb}$ method, to be about 200 years old. The use of ${ }^{210} \mathrm{~Pb}$ as a chronometer requires some form of independent check. So the age of sediments was also determined using ${ }^{137} \mathrm{Cs}$ radionuclide.

At first the radioactivity of total ${ }^{210} \mathrm{~Pb}$ was evaluated. In this profile the radioactivity of ${ }^{210} \mathrm{~Pb}_{\text {total }}$ ranged from $16.7 \pm 1.5$ to $1,258 \pm 99 \mathrm{~Bq} \mathrm{~kg}^{-1}$. Due to the fact that Smreczynski Staw Lake is a glacial lake, the radioactivity of the deepest layers is ascribed to the radioactivity of ${ }^{210} \mathrm{~Pb}_{\text {sup }}$, which equals $17.9 \pm 1.5 \mathrm{~Bq} \mathrm{~kg}^{-1}$. Calculated values of the radioactivity of unsupported lead in the measured profile are at the same level as found in other Tatra lakes located in Poland [3]. The radioactivity of ${ }^{210} \mathrm{~Pb}_{\text {uns }}$ in superficial sediments collected from the Zielony Staw Gasienicowy Lake and the Dlugi Staw Gasienicowy Lake is about $1,000 \mathrm{~Bq} \mathrm{~kg}^{-1}$ as in the Smreczynski Staw Lake. Similar values were determined in a mountainous lake in Norway [2]. In all the above mentioned lakes, a systematic decrease with depth of ${ }^{210} \mathrm{~Pb}_{\text {uns }}$ radioactivity was reported.

The same tendency was found in other lakes in the Tatras; namely: Niżne Terianskie Pleso Lake and Ladove Pleso Lake [3].

Based on the results of radio dating it was assumed that the $12,5 \mathrm{~cm}$ sediment core represents the sediments from the last 176 years.

Age span of the analyzed sediments core covered 176 years of the Smreczynski Staw Lake's "sedimentary" history. Radioactivity of ${ }^{210} \mathrm{~Pb}_{\text {uns }}$ was the highest in the year of sampling (2010) and, as a result of the radioisotope decay, decreased with the depth of the layer (Fig. 3). Sediment layer age and depth in the core allowed calculation of the sedimentation rate and mass accumulation rate. The average sedimentation rate in this profile was calculated to be about $0.07 \mathrm{~cm}_{\text {year }}{ }^{-1}$. The overall decrease in sedimentation rate reflects the processes of compaction and other processes involved in a sediments' diagenesis. This phenomena was also confirmed by calculating the 
Fig. 3 Changes in ${ }^{210} \mathrm{~Pb}_{\text {uns }}$ concentration in the sediments core samples

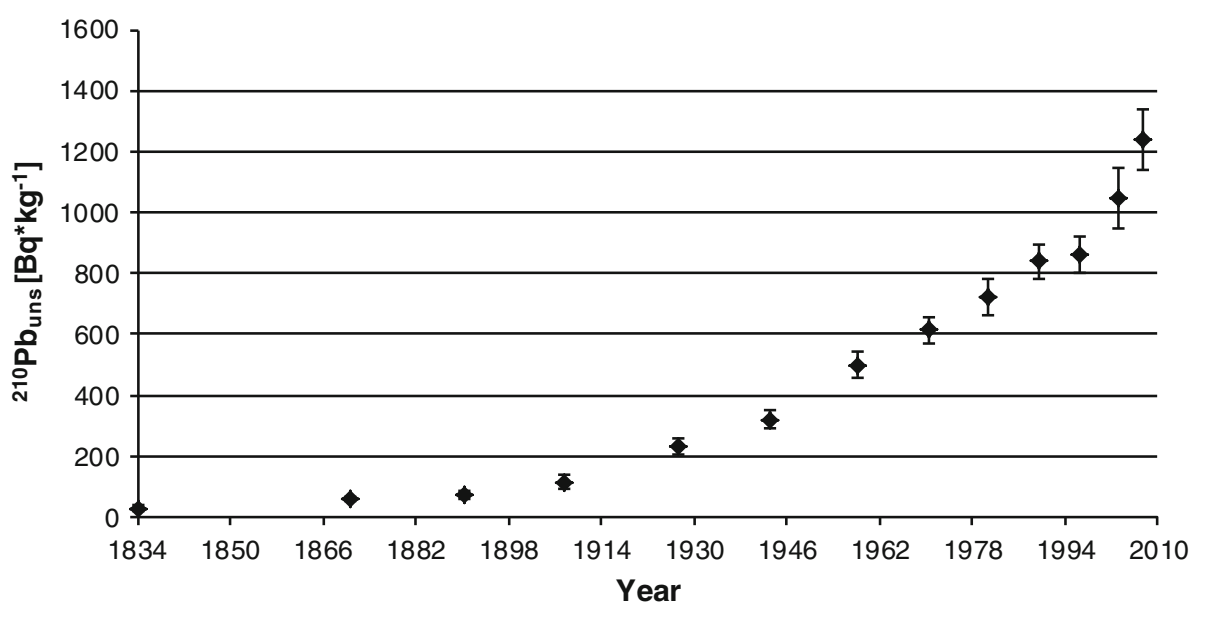

mass accumulation rate, which ranged from 0.0003 to $0.0013 \mathrm{~g} \mathrm{~cm}^{-2}$ year ${ }^{-1,}$ and varied over the analyzed period of time. It was noted that with the increase in sedimentation rate, the mass accumulation rate also reached a higher value. The obtained values of mass accumulation rates were 5 times lower than the values determined for the Ladove Pleso Lake. But in the latter case the higher values of mass accumulation rates were attributed to rapid rock landslides [19].

Considering the radioactivity of ${ }^{137} \mathrm{Cs}$ in the core sediment samples, variation was found to be between $89 \pm 11$ and $865 \pm 62\left(\mathrm{~Bq} \mathrm{~kg}^{-1}\right)$. These data are comparable with cesium radioactivity measured in the sediments of the Zielony Staw Gasienicowy Lake (High Tatras), but are much lower than that found in the sediments of other Tatra lakes like the Nizne Tatranskie Pleso Lake or Ladove Pleso Lake [3].

The decreasing level of ${ }^{137} \mathrm{Cs}$ radioactivity with the increasing depth of the sediments of the Smreczynski Staw Lake was observed (Fig. 4). High cesium radioactivity in the near surface sediments layer, can be ascribed to the Chernobyl fallout (1986). An impact from weapon tests on ${ }^{137} \mathrm{Cs}$ radioactivity is also visible, but due to the close proximity to the surface sediments, weapon ${ }^{137} \mathrm{Cs}$ is almost certainly obscured by a downward migration of Chernobyl ${ }^{137} \mathrm{Cs}$. Despite this fact, cesium is treated as a time marker for the relevant sediment layer.

The presence of cesium between the $3.5-4.5 \mathrm{~cm}$ layer, is probably connected with the Chernobyl accident (1986). The $5.5-6.5 \mathrm{~cm}$ layer, may be attributed to the weapon testing. These data were confirmed by ${ }^{210} \mathrm{~Pb}$ dating. Sediments in the depth range $3.5-4.5 \mathrm{~cm}$ correspond to the period 1981-1989 and at a depth ranging between 5.5 and $6.5 \mathrm{~cm}$ were assigned to the period 1958-1970. So as previously mentioned, both these ranges are connected with the time when the cesium radioactivity was at the elevated level.
Futhermore, in the deeper layers certain amounts of the cesium radionuclide were also detected. This fact relates to its mobility in the sediments [8]. In the Smreczynski Staw Lake the sediments are rich in water and organic matter, conditions which favour the transfer of ${ }^{137} \mathrm{Cs}$ radionuclide down the core.

The slight decrease in ${ }^{137} \mathrm{Cs}$ radioactivity in the youngest layer of the core is attributed to the lack of new sources of the radionuclide in the environment and to its natural decay.

So the collected samples, based on the ${ }^{210} \mathrm{~Pb}$ method, were dated back to 1834 and the sediments composition comprises about 180 years of Tatras history (Table 1).

Despite the fact that the sediments were deposited over such a long period of time, some parameters differed little; namely: pore water $\mathrm{pH}$ was in the range 4.4-4.6, no coarse material was found (sediments had a pellitic form) and TOC increased with depth from $62.3 \%$ in the top (youngest) segment to $81.4 \%$ in the deepest $(16 \mathrm{~cm})$ sediment layer.

It was discovered that of 8 analyzed elements, 6 were present in the sediments in the deepest-oldest sediment core layer in significant concentrations. Undoubtedly, it results directly from the mother rock leaching and elements being transported in the ecosystem. Some of the elements are present in the sediments in high concentrations (data for 1834)—Fe: 3923 ppm (Fig. 5a), Zn: 135 ppm (Table 1), others in lower concentrations, (e.g. Mn: 38 ppm (Fig. 5b), $\mathrm{Pb}: 146 \mathrm{ppm}$ (Fig. 6)), while some of them are present in much lower concentrations, such as $\mathrm{Cu}: 18.4 \mathrm{ppm}$, and $\mathrm{Ni}$ : $3.07 \mathrm{ppm}$ (Table 1). Cadmium is the only element determined that appears in extremely low concentrations in the deepest layers-below 1 ppm (Fig. 7).

The observed course of changes in metals concentrations in the sediments core can be divided into three periods. The first period covering the years from 1834 until the end of the 19th century, the second from the 1930s to the 1990s and the last from then on. 
Fig. 4 Changes in cesium-137 concentration in the sediments core samples

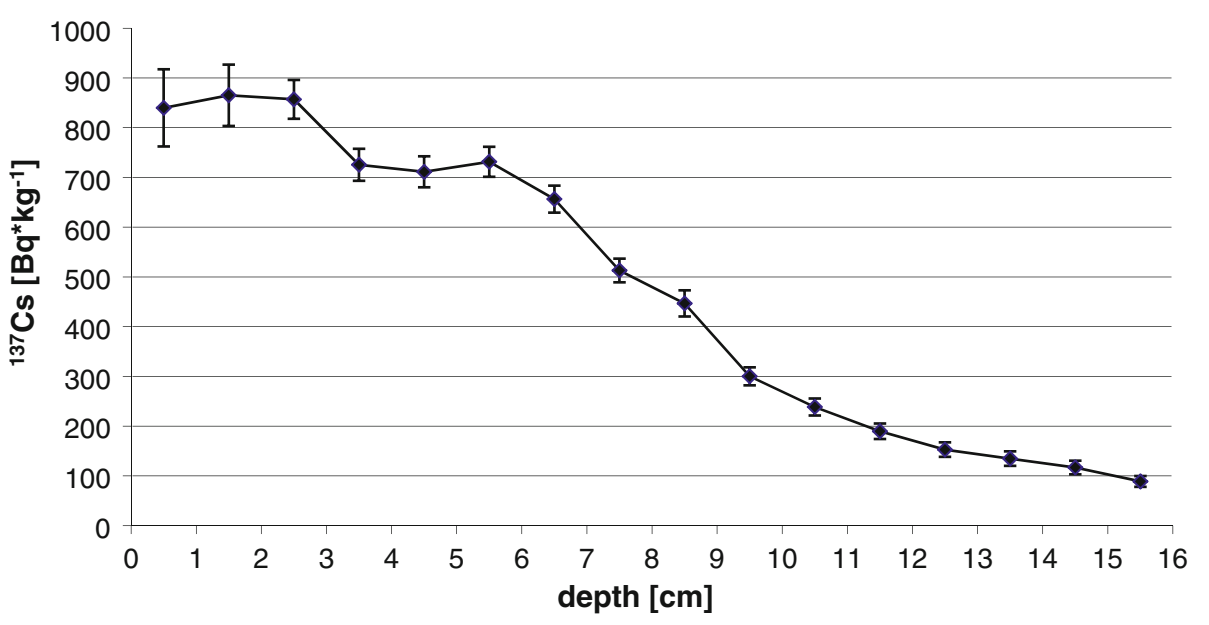

Table 1 Elements concentrations in $\left(\mu \mathrm{g} \mathrm{g}^{-1}\right)$ the sediment's core of the Smreczynski Staw Lake

\begin{tabular}{llccc}
\hline \multirow{2}{*}{ Depth } & $\begin{array}{l}\text { Deposition } \\
\text { time (years) }\end{array}$ & \multicolumn{3}{l}{ Element concentration $\pm \mathrm{SD}$} \\
\cline { 3 - 5 } & & $\mathrm{Zn}$ & $\mathrm{Cu}$ & $\mathrm{Ni}$ \\
\hline 12.5 & 1834 & $382 \pm 40$ & $18.37 \pm 0.68$ & $3.07 \pm 0.23$ \\
11.5 & 1871 & $479 \pm 24$ & $21.9 \pm 1.9$ & $5.21 \pm 0.22$ \\
10.5 & 1890 & $441.8 \pm 7.5$ & $23.1 \pm 2.2$ & $5.57 \pm 0.14$ \\
9.5 & 1908 & $457.2 \pm 1.7$ & $19.6 \pm 1.3$ & $6.2 \pm 1.2$ \\
8.5 & 1927 & $400.0 \pm 1.9$ & $19.9 \pm 1.9$ & $7.08 \pm 0.33$ \\
7.5 & 1943 & $285.6 \pm 5.3$ & $28.8 \pm 2.8$ & $7.83 \pm 0.79$ \\
6.5 & 1958 & $184.7 \pm 5.1$ & $34.5 \pm 2.1$ & $10.17 \pm 0.84$ \\
5.5 & 1970 & $172.0 \pm 3.5$ & $36.0 \pm 1.7$ & $10.49 \pm 0.90$ \\
4.5 & 1981 & $132.9 \pm 3.5$ & $36.3 \pm 1.5$ & $10.20 \pm 0.67$ \\
3.5 & 1989 & $134 \pm 18$ & $43.6 \pm 2.4$ & $10.8 \pm 1.2$ \\
2.5 & 1996 & $166 \pm 61$ & $29.4 \pm 1.7$ & $10.34 \pm 0.52$ \\
1.5 & 2003 & $130.7 \pm 8.6$ & $32.5 \pm 1.5$ & $10.53 \pm 0.44$ \\
0.5 & 2007 & $131.9 \pm 4.1$ & $30.3 \pm 2.4$ & $8.75 \pm 0.71$ \\
\hline
\end{tabular}

The concentrations of iron and manganese, which represent constituent elements of the rocks, changed little during the first period ( $\mathrm{Fe}$ was in the range from 3,799 to 3,923 ppm; $\mathrm{Mn}$ in the range 38.5-31.1 ppm) (Fig. 5a, b). But since 1927 a marked increase in iron concentration in the sediments has been noted (the highest concentration was found in 1981). This was a result of transportation from afar of contaminants and acid rain, rather than local contamination due to iron ore excavation and development of local industry, such as smelters and forges a few kilometers from the lake (Fig. 2). From the beginning of the 1970s the practice of environmental protection began. The breakthrough came in the 1990s when the treaty was signed in which the environment was the main objective of the European Community's action plan. These activities and the simultaneous economic crisis in Eastern Europe were the reason for substantial reduction in air pollution. As a consequence, contamination of water and sediments was reduced. The same tendency was also noted for manganese, but the range of concentration changes was much narrower (from 42 to $51 \mathrm{ppm}$ ) (Fig. 5b).

As was mentioned before, $\mathrm{Cu}$ ores have been excavated in the Western Tatras since the 15th century (Fig. 2), so some increase in the element concentration in the sediment samples dating back to the 19th century was measured (Table 1). Furthermore, a much more substantial increase in $\mathrm{Cu}$ concentrations were found in the samples from the 20 th century. But at the end of the 20th century there was little decrease in concentration levels.

A marked increase in $\mathrm{Pb}$ levels in the samples from the 20th century might be attributed, despite natural leaching from the mother rock, to the air pollution resulting from the development of road transport (Fig. 6).

Concentrations of $\mathrm{Cr}$ and $\mathrm{Cd}$ in the core sediment samples have changed in a similar manner (Fig. 7). However, initially the cadmium concentration was the lowesta very low natural concentration of the element in the mother rocks and soils (or strong binding of the element in minerals), compared to $\mathrm{Cr}$. But the tendencies in those concentrations of elements were the same as for the other metals, i.e. lowest and most stable concentration in the first period, steep increase in the 20th century followed by a decrease.

Some interesting information can be drawn out if one compares the changes of the concentrations of the chosen 5 heavy metals, relative to the findings of 1834 (Fig. 8a) and 1989 (Fig. 8b). Since the year 1834, of 8 selected elements only one revealed a substantial increase, i.e. $\mathrm{Cd}$ (its share increased from 0.02 to $0.5 \%$ ). As we look at the concentration values, the increase in the elements share is a result of serious environment contamination (for $\mathrm{Cd}$ the increase is dramatic from 0.8 to $34.1 \mathrm{ppm}$; the increase for $\mathrm{Pb}$ is also substantial from 146 to $352 \mathrm{ppm}$ ). The changes for other metals are negligible. This confirms the 
Fig. 5 Changes in iron (a) and manganese (b) concentrations in the sediments core samples

Fig. 6 Changes in lead concentration in the sediments core samples
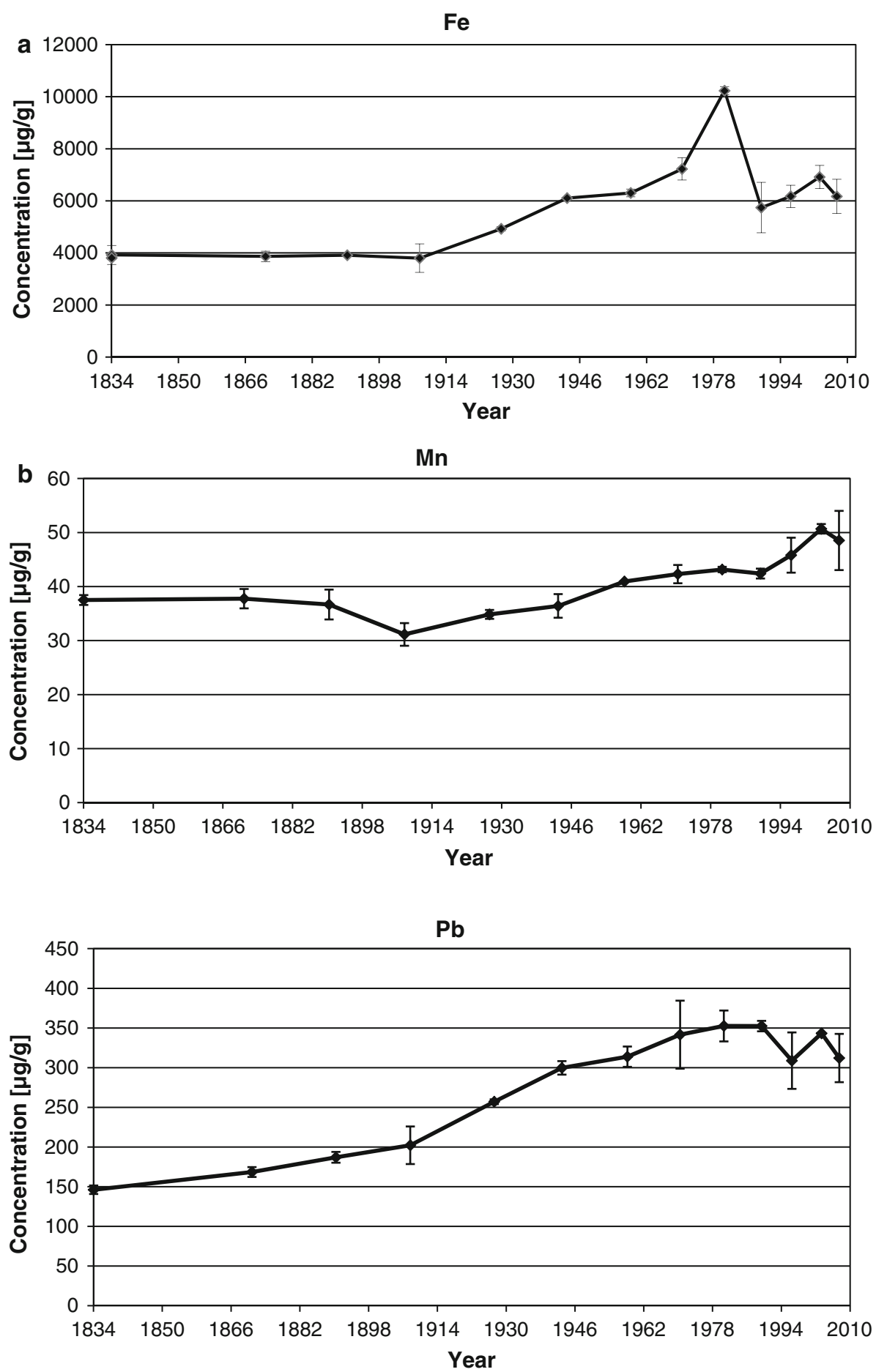

assumption that those elements present in the sediments is natural and is a result of washing out from the mother rock and soil.

\section{Conclusions}

Based on the performed chemical and radiochemical analyses the following facts were established:
1. Sediments constitute a very useful tool for a water environment quality assessment.

2. Concentrations of all analysed elements in the sediment core of the Smreczynski Staw Lake have increased over time, but most significantly since the beginning of the 20th century.

3. Environmental protection activities in Europe bring positive results, as the analysed metal concentrations have decreased markedly in the most recent years. 
Fig. 7 Changes in cadmium and chromium concentrations in the sediments core samples

Fig. 8 Comparison of the fraction of elements in the sediments deposited around 1834 (a) and 1989 (b)

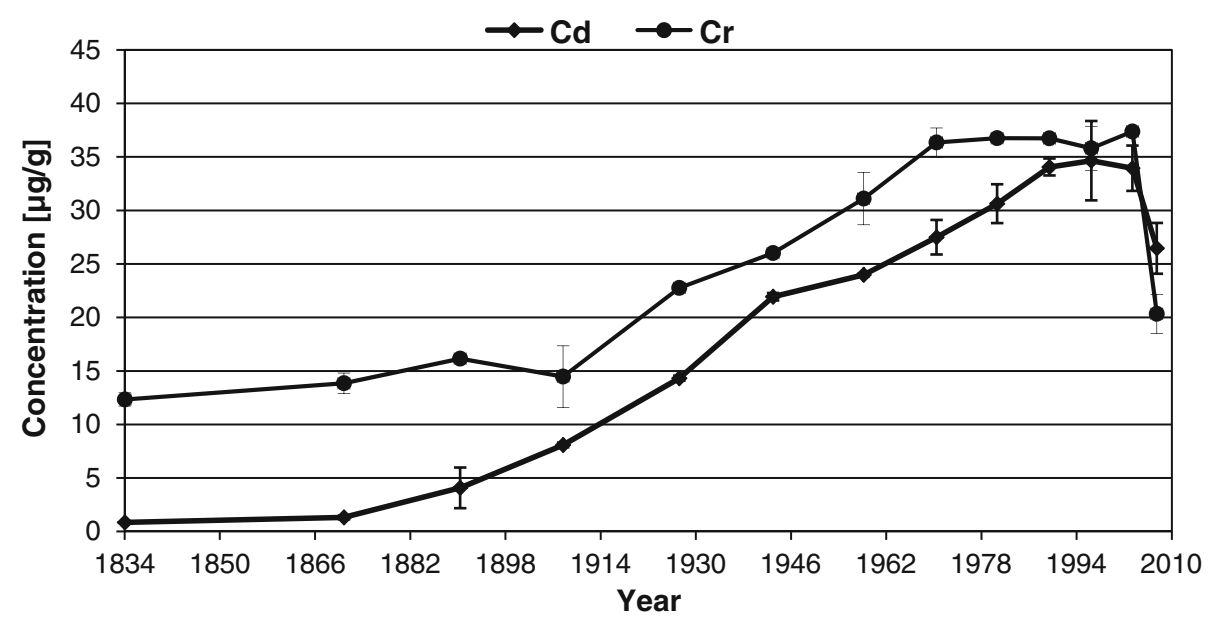

a

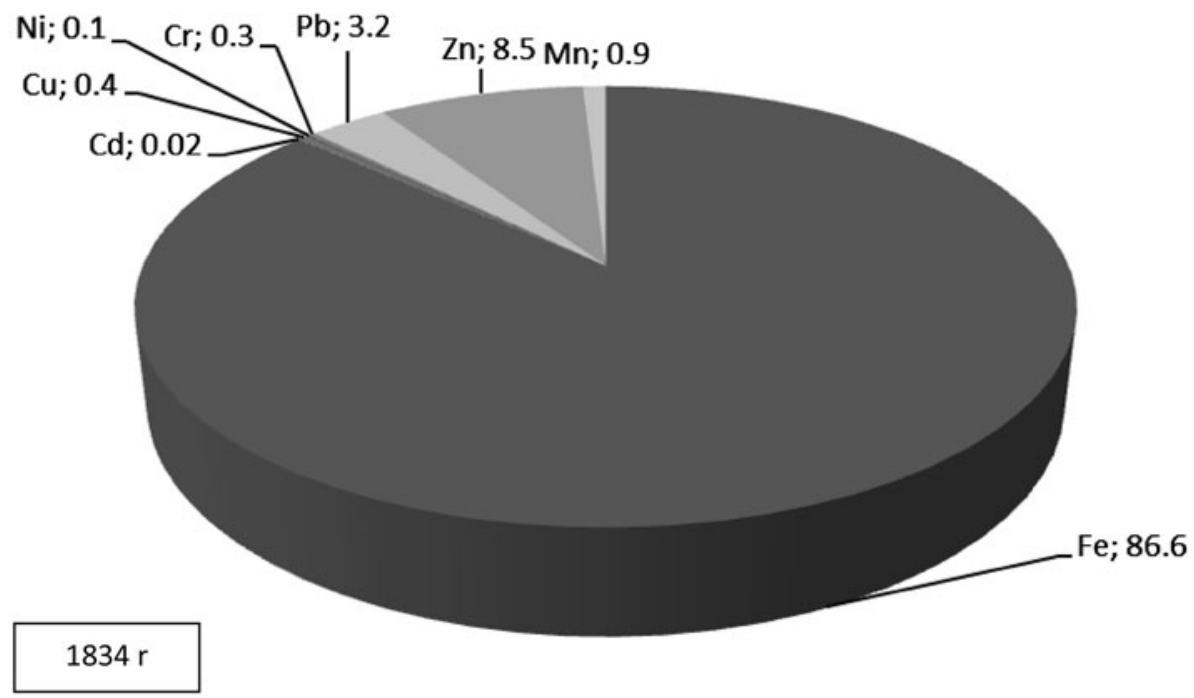

b

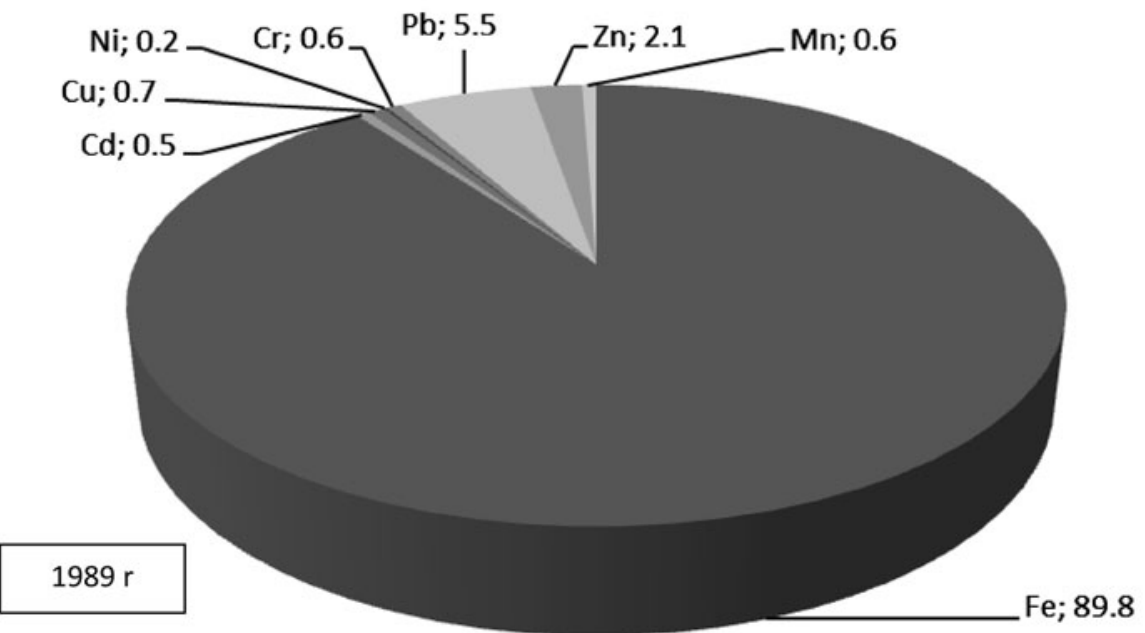


4. Estimated age of sediment using the ${ }^{210} \mathrm{~Pb}$ method was confirmed by use of the ${ }^{137} \mathrm{Cs}$ method.

Considering the history of industrialization in the Tatra Mountains, the impact of human activity on the environment up to the end of the 19th century did not pose a serious threat to the living organisms where heavy metals are discussed. Our initial observation has been confirmed by the obtained results. The heavy contamination of the environment since the beginning of the industrial revolution was also confirmed. Undoubtedly, the applied methodology might be useful in the analyses of the history of site contamination and can be a reference for discussions in other scientific fields (e.g. mineralogy, history, geochronology, ethnography etc.).

Acknowledgments The authors would like to thank the first deputy head of the Tatra NationalPark, Dr Zbigniew Krzan and mgr inż. Marek Peksa for their help and assistance with this project. This study was supported by the AGH University under Grant numbers 11.11.160.799 and 11.11.210.244.

Open Access This article is distributed under the terms of the Creative Commons Attribution License which permits any use, distribution, and reproduction in any medium, provided the original author(s) and the source are credited.

\section{References}

1. Andersson C, Langner J (2007) Inter-annual variations of ozone and nitrogen dioxide over europe during 1958-2003 simulated with a regional CTM. Water Air Soil Pollut 7:15-23

2. Appleby PG (2000) Radiometric dating of sediments records in European mountain lakes. Limnology 59(1):1-14

3. Appleby PG, Piliposian GT (2006) Radiometric dating of sediment records from mountains lakes in the Tatra Mountains. Biologia Bratislava 18:51-64

4. Bak B, Piestrzynski A, Radwanek-Bak B (1996) Mining traces in the Polish West Tatras. In: Krzan Z (ed) The nature of the tatra national park and a man. T.3 the anthropogenic influence. TPN Publishing and Earth Sciences Society, Zakopane in Polish

5. Bem H (2005) Radioactivity in natural environment. PAN, Łodz in Polish

6. Carroll J, Williamson M, Lerche I, Karabanov E, Williams DF (1999) Geochronology of Lake Baikal from ${ }^{210} \mathrm{~Pb}$ and ${ }^{137} \mathrm{Cs}$ radioisotopes. Appl Radiat Isot 50:1105-1119

7. Christensen ER, Goetz RH (1987) Historical fluxes of particlebound pollutants from deconvolved sedimentary records. Environ Sci Technol 21:1088-1096

8. Dolhańczuk-Srodka A, Waclawek M (2007) Cesium-137 translocation in environment. Ecol Chem Eng T14(S2):147-169

9. Du P, Walling DE (2011) Using ${ }^{137} \mathrm{Cs}$ measurements to investigate the influence of erosion and soil redistribution on soil properties. Appl Radiat Isot 69:717-726

10. Dube A, Zbytniewski R, Kowalkowski T, Cukrowska E, Buszewski B (2001) Adsorption and migration of heavy metals in soils. Pol J Environ Stud 10(1):1-10
11. Flynn WW (1968) The determination of low levels of polonium210 in environmental materials. Anal Chim Acta 43:221-227

12. Forsius M, Kleemola S, Vuorenmaa J, Syri S (2001) Fluxes and trends of nitrogen and sulphur compounds at integrated monitoring sites in Europe. Water Air Soil Pollut 130:1641-1648

13. Gasiorowski M, Sienkiewicz E (2010) The little ice age recorded in sediments of a small dystrophic mountain lake in southern Poland. J Paleolimnol 43:475-487

14. Grim RE (1968) Clay mineralogy. Mc Graw-Hill Book C, New York

15. Hjellbrekke AG, Tarrason L (2001) Mapping of concentrations in Europe combining measurements and acid deposition models. Water Air Soil Pollut 130:1529-1534

16. Hrynkiewicz AZ (2001) Human and ionizing radiation. PWN, Warsaw in Polish

17. Jost H (1962) About mining and metallurgy in the Polish Tatras. WNT, Warsaw in Polish

18. Jost $H$ (1993) Industry on the Tatra National Park area. In: Cichocki W (ed) The Tatra Mountains Protection. The Tatra Mountains Museum Publishing, Zakopane in Polish

19. Kotarba A, Lokas E, Wachniew $\mathrm{P}(2002){ }^{210} \mathrm{~Pb}$ dating of young halocene sediments in high-mountains lakes of the Tatra mountains. Geochronometria 21:73-77

20. Kubica B, Skiba S, Mietelski JW, Golas J, Kubica M, Stobinski M, Tuteja-Krysa M, Tomankiewicz E, Gaca P, Krzan Z (2004) Transect survey of artificial ${ }^{137} \mathrm{Cs}$ and natural ${ }^{40} \mathrm{~K}$ in moss and bilberry leaf samples from two main valleys from Tatra National Park. Pol J Environ Stud 13:153-159

21. Lubis AA (2006) Constant rate of supply (CRS) model for determining the sediment accumulation rate in the coastal area using ${ }^{210} \mathrm{~Pb}$. J Coast Dev 10(1):9-18

22. McCafeferty RJ, Thomson J (1980) A record of accumulation of sediment and trace metals in a Connecticuit salt marsh. Adv Geophys 22:165-236

23. Mirek Z (1996) Anthropogenic threats and environmental changes. In: Mirek Z (ed) The nature of the Tatra National Park. TPN Publishing, Zakopane in Polish

24. Misiak R, Hajduk R, Stobinski M, Bartyzel M, Szarlowicz K, Kubica B (2011) Self-absorption correction and efficiency calibration for radioactivity measurement of environmental samples by gamma-ray spectrometry. Nukleonika 56(1):23-28

25. Norton SA (2007) Atmospheric metal pollutants-archives, methods, and history. Water Air Soil Pollut 7:93-98

26. Sabaris TPP, Bonotto DM (2011) Sedimentation rates in Atibaia River basin, Sao Paulo State, Brazil, using ${ }^{210} \mathrm{~Pb}$ as geochronometer. Appl Rad Isot 69:275-288

27. Schulte-Rentrop A, Costa-Cabral M, Vink R (2005) Modeling the overland transport of lead deposited from the atmosphere in the elbe catchment over four decades (1958-1995). Water Air Soil Pollut 160:271-291

28. Sikorski J, Bluszcz A (2008) Application of $\alpha$ and $\gamma$ spectrometry in the ${ }^{210} \mathrm{~Pb}$ method to model sedimentation in artificial retention reservoir. Geochronometria 31:65-75

29. Torseth K, Wench AAS, Sverre S (2001) Trends in airborne sulphur and nitrogen compounds in norway during 1985-1996 in relation to air mass origin. Water Air Soil Pollut 130:1493-1498

30. Ugur A, Miquel JC, Fowler SW (2003) Radiometric dating of sediment cores from a hydrothermal vent zone off Milos Island in the Aegean Sea. Sci Total Environ 307:203-214

31. Zbytniewski R, Buszewski B (2002) Test some aspects of modeling sorption of hydrophobic compounds in soils. Advert Sci Technol 20(3):231-242 